BMJ Open Sport \& Exercise Medicine

\title{
Single-leg balance and core motor control in children: when does the risk for ACL injury occurs?
}

\author{
Allison B Hutchinson, Paul Yao, Mark R Hutchinson
}

To cite: Hutchinson $A B$, Yao P, Hutchinson MR. Single-leg balance and core motor control in children: when does the risk for $\mathrm{ACL}$ injury occurs?. BMJ Open Sport Exerc Med 2016;2: e000135. doi:10.1136/ bmjsem-2016-000135

- Prepublication history for this paper is available online. To view these files please visit the journal online (http://dx.doi.org/10.1136/ bmjsem-2016-000135).

Accepted 23 May 2016

\section{ABSTRACT}

Introduction: While numerous publications have demonstrated the correlation of poor single-leg balance and core motor control with an increased risk of anterior cruciate ligament (ACL) injuries in skeletally mature female athletes, few have analysed the preadolescent population regarding when indeed comparative deficits in balance and core control actually occur. The purpose of this study was to assess whether the neuromotor factors that place mature females at increased risk of ACL injury actually are present in preadolescents and if so when.

Methods: This study used simplified modifications of classic drop-jump testing as well as single-leg balance tests performed on stable and unstable surfaces to assess balance and core motor control. 84 children (males and females) ranging in age from 6 to 13 years were divided into 4 equally sized groups based on their academic classes. Each group was compared with each other, and compared with a cohort of 205 collegiate athletes. The latter served as a comparative norm of mature athletes who had performed the same or similar testing.

Results: Outcomes revealed that the preadolescent population performed poorly on the tests when compared with the collegiate population but the children matured with age until the eldest subgroups compared more favourably with the college-aged athletes. Girls appear to mature at a slightly earlier pace than boys. This study focusing on preadolescent children concluded that the neuromuscular changes that place females at greater risk of injury do not appear to occur prior to adolescence.

Conclusions: Based on the outcomes of this study, it is suggested that sex differences regarding balance and core control deficits that can increase risk of ACL injuries likely occur after grade school (age 12-13).

\section{INTRODUCTION}

The relative increased risk of anterior cruciate injury in women compared with men in twisting and cutting sports has become well recognised and well documented in the literature. ${ }^{1-3}$ While numerous factors including anatomic alignment, hormonal influences and anatomic structure (small notch, smaller ligament volume) have been considered and in some

\section{Key findings}

- Regarding jump landing and balance skills, girls mature earlier than boys.

- Regarding jump landing and balance skills, factors that predispose mature women to anterior cruciate ligament injuries have not yet appeared in preadolescents.

- Regarding jump landing and balance skills, young children perform more poorly than college-aged cohorts.

- Regarding jump landing and balance skills, mature children (age 12-13) perform similar to college-aged cohorts.

cases implicated as causative factors, neuromotor retraining of core and balance deficiencies has been shown to be an effective means of injury prevention in these at-risk athletes. ${ }^{3-5}$ More specifically, studies of adolescent and young adult athletes have revealed sex variation of core and neuromotor control when comparing trained and untrained athletes with positive response to neuromuscular retraining. ${ }^{6-13}$ This is especially true for female athletes. Indeed, in the position statement of the National Athletic Trainer's Association, they determined that to the highest level of evidence, they could recommend prevention programmes focusing on neuromuscular control, balance, coordination, flexibility and strength to reduce the risk of overuse injuries in the paediatric population. ${ }^{14}$

The questions raised and targeted in this study are: at what age does the sex-related imbalance of lower limb neuromotor control in preadolescent children occur, and how do children progress regarding neuromotor skills with maturity. $6 \quad 8 \quad 1516$ We hypothesised that children would have poorer neuromotor control compared with collegiate athletes, that they would improve with maturity, and that we could identify a predictive age group for which girls lagged behind boys in development of neuromotor control placing them at risk of anterior cruciate ligament (ACL) injury. 


\section{MATERIALS AND METHODS}

Eighty-four children, 42 boys and 42 girls, age range 6-13 with equal distribution between first and eighth grade at an American grade school were prescreened for eligibility. Participants were asked to volunteer and each required parental consent. Many were recruited at school-wide events in which both student and parent were present. None were recruited at athletic events in which a more athletic population might be expected to skew the results. Participants were disqualified if they had a lower extremity injury within 6 months of the testing. History of lower extremity injury $>6$ months old as well as pretest participation in a balance, twisting or cutting sport were recorded. For comparison, the cohort was divided into four comparison groups: first and second grade ( $\sim 6-7$ years old); third and fourth grade ( $\sim 8$ 9 years old), fifth and sixth grade ( 10-11 years old), and seventh and eighth grade ( 12-13 years old). All participants signed or had their parents sign an individual consent for participation. The project itself was approved after institutional review.

Each participant underwent a series of neuromotor screening tests. A single evaluator measured all preadolescent participants to avoid inter-rater variability. Single-leg squats were performed on stable and unstable surfaces based on techniques previously reported and validated in the literature in adult populations. ${ }^{11} 1713$ Each participant was asked to assume a single-legged stance. Once they were stable, the participant was asked to squat down to a knee flexion angle of $90^{\circ}$ and rise back to full extension while maintaining an erect torso. The ability to maintain balance as well as maintain knee varus/valgus alignment were assessed and recorded. These were scaled from 1 (normal) to 5 (abnormal requiring step down; figure 1). Each participant repeated the test and their best score was used for comparison in the study. Next, each participant was also assessed performing a modified two-legged drop-jump test based on previously described techniques in the literature. ${ }^{11} 13$ These were scaled on a 1-5-point scale with 3 being ideal and 1 being excessive valgus and 5 being excessive varus (figure 2). The classic two-legged dropjump test was modified for simplicity for participants of all ages. Basically, the participant was asked to jump down from a height of a 12-inch box and land with both feet simultaneously. No second plyometric jump onto a second box was performed. Each participant repeated the test and their best score was used for comparison in the study.

In total, 228 mature, collegiate athletes aged 17-24 years (118 males/110 females) underwent the same, scaled, single-leg squat assessment on stable and unstable surfaces. The collegiate athletes served as a comparative cohort not a control group. Twenty-three athletes were disqualified due to recent (within 6 months) lower extremity injury leaving 205 athletes (410 knees) for comparison. The collegiate athletes participated in a variety of sports including baseball, basketball, gymnastics, soccer, softball, swimming, tennis, track and cheerleading.

Statistical analysis was performed by an independent statistician using $\chi^{2}$, Student's t-test and Fischer's t-test for group comparisons. Statistical significance was set a priori at $p>0.05$. If trends were identified that did not meet that criteria, special notation was included documenting the inability to conclude statistical significance.

\section{RESULTS}

Comparison of the grade school cohort to the collegiate cohort revealed overall poorer balance and lower extremity neuromotor control in the all of the grade school cohort compared with athletic collegiate athletes. For single-leg balance on a stable surface, the average grade school score was $2.15 \pm 0.11$ (normal being 1) compared with the collegiate athletes who scored 1.8 \pm 0.1 $(p<0.05)$. For single-leg balance on an unstable surface, the grade school cohort scored $2.61 \pm 0.11$ compared with the collegiate athletes who scored $2.2 \pm 0.1 \quad(\mathrm{p}<0.05)$. When the 12-13 years old subgroup was compared with the college athletes, the differences were less significant (stable 1.7 compared with 1.8 in collegiate athletes, unstable 2.4 compared with 2.2 in collegiate athletes). Evaluating test-retest outcomes revealed that testing
Figure 1 Scoring scale for single-leg balance test. One is a perfect score, 5 is a failed score requiring the participant to place contralateral foot on the ground. A score of 2 represents a poor hip control with dropped hip and slight valgus of tested knee. A score of 3 demonstrates the participant introducing the upper extremities to maintain balance and upper torso motion. A score of 4 represents significant upper extremity and torso movement beyond central balance line and a near failure.

\section{Balance Scale}

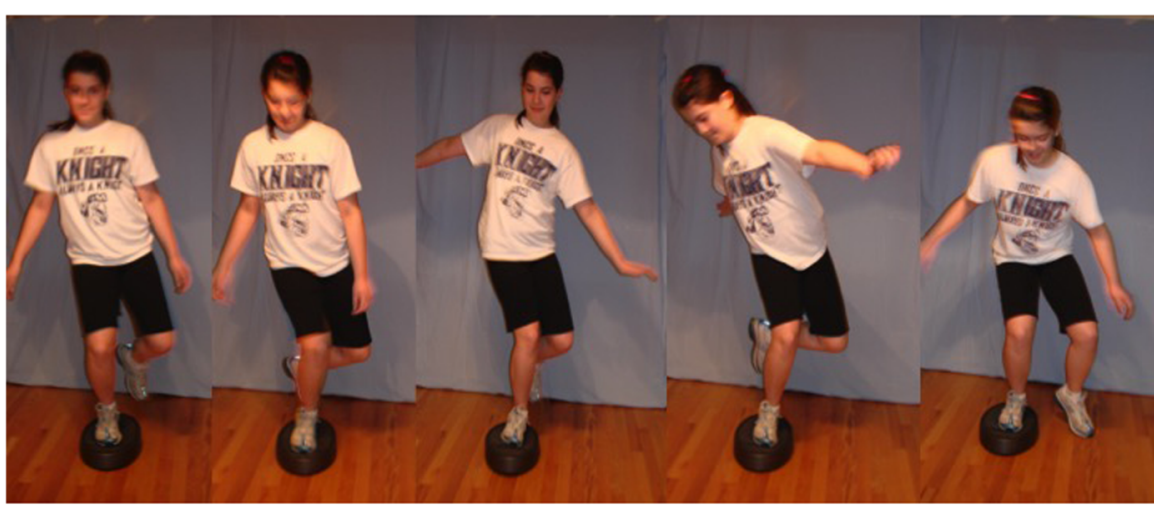

1
2
3
4
5 
Figure 2 Scoring for modified drop-jump test. A score of 3 is ideal with neutral position of the knees over the foot with no varus or valgus deformity. A score of 2 demonstrates mild valgus with some portion of the knee still above the foot. A score of 4 represents mild varus with some portion of the knee still above the foot. A score of 1 or 5 represents extreme varus or valgus position on landing.

\section{Drop Jump Scale}

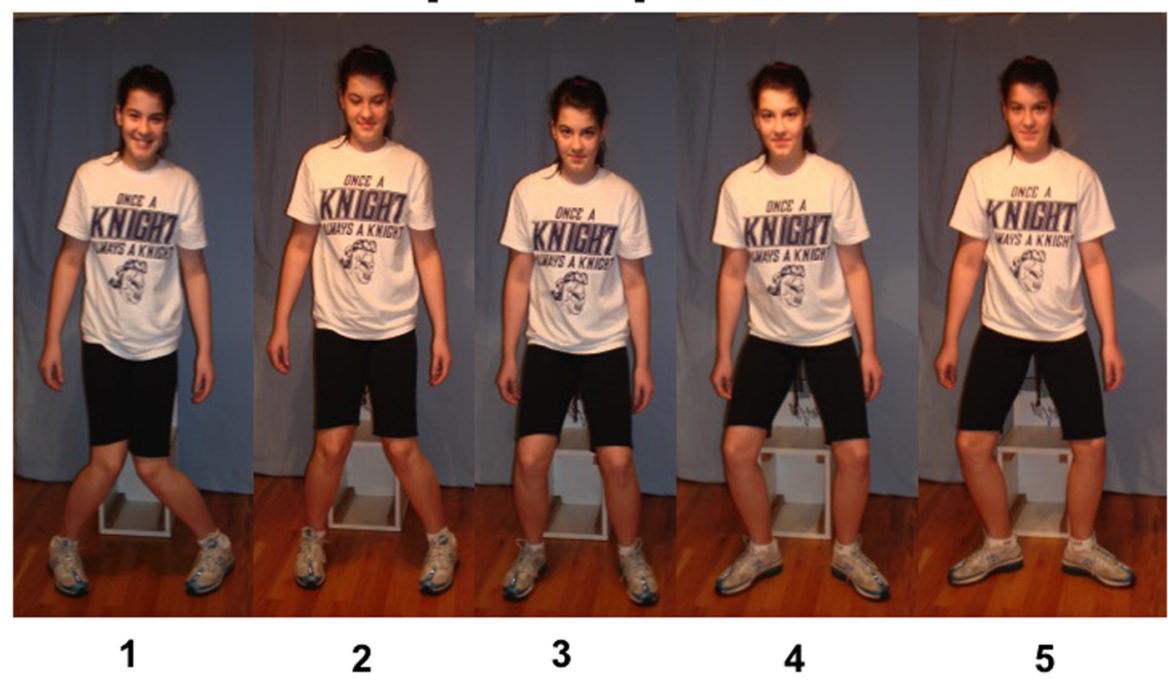

occur between the 8-9 and the 10-11 years old subgroups. No significant difference were noted when comparing children with a distant history of lower extremity injury (13/84) and those with no such history $(71 / 84)$ based on single-leg squats on an unstable surface (2.58 compared with 2.68 score, respectively).

When comparing by sex the performance of children on the stable and unstable surface, girls appear to mature slightly earlier than boys. Indeed a significant jump in performance on the stable platform occurs for girls between the ages of 6-7 and 8-9 years $(\mathrm{p}<0.003)$, while significant improvement for boys occurs on the stable and unstable platforms between 8-9 and 1011 years old $(\mathrm{p}<0.03$ and $\mathrm{p}<0.003$, respectively; table 2$)$.

Based on direct sex comparison of each age subgroup of the children using the drop jump and single-leg balance as measures, results failed to reveal a specific timeframe in which females began to lag behind their male counterparts. The only $\chi^{2}$ analyses that achieved statistical significance were: girls aged 6-7 years were better than the boys with right leg squats on a stable surface $(p<0.07)$; girls aged $8-9$ years were better than the boys with left leg squats on a stable surface $(\mathrm{p}<0.003)$; and girls aged 8-9 years were better than the boys with left leg squats on unstable surface $(p<0.04$;

Table 2 Maturation of balance scores college norms

\begin{tabular}{lll}
\hline Preadolescent & College & Significance \\
\hline$(\mathrm{N}=84)$ & $(\mathrm{N}=410)$ & \\
Stable & Stable & \\
$2.15 \pm 0.11$ & $1.8 \pm 0.1$ & $\mathrm{p}<0.05$ \\
Unstable & Unstable & \\
$2.61 \pm 0.11$ & $2.2 \pm 0.1$ & $\mathrm{p}<0.05$ \\
$\mathrm{p}<0.005$ & $\mathrm{p}<0.005$ & \\
\hline
\end{tabular}

Comparison of all preadolescent participants and all collegiate athletes when performing balance testing on a stable and unstable surface. The data reveal significant differences between both participant cohorts and testing techniques.

\begin{tabular}{|c|c|c|c|c|}
\hline \multirow[b]{2}{*}{ Age } & \multicolumn{2}{|c|}{ Stable surface } & \multicolumn{2}{|c|}{ Unstable surface } \\
\hline & Girls & Boys & Girls & Boys \\
\hline $6-7$ & $2.13 \pm 0.19$ & $2.48 \pm 0.24$ & $2.41 \pm 0.28$ & $2.77 \pm 0.30$ \\
\hline $8-9$ & $1.72 \pm 0.19$ & $2.28 \pm 0.23$ & $2.57 \pm 0.26$ & $2.72 \pm 0.20$ \\
\hline $10-11$ & $1.78 \pm 0.21$ & $1.83 \pm 0.23$ & $2.48 \pm 0.25$ & $2.25 \pm 0.25$ \\
\hline $12-13$ & $1.66 \pm 0.19$ & $2.01 \pm 0.29$ & $2.29 \pm 0.24$ & $2.25 \pm 0.28$ \\
\hline \multicolumn{5}{|c|}{$\begin{array}{l}\text { Comparison of maturation of balance skills of preadolescent } \\
\text { participants by age subgroups. Significant improvement is noted } \\
\text { for girls between ages } 6-7 \text { and } 8-9 \text { years. Significant } \\
\text { improvement is noted for boys between ages } 8-9 \text { and } \\
10-11 \text { years. }\end{array}$} \\
\hline
\end{tabular}


Is there an age in which one gender is better than the other?
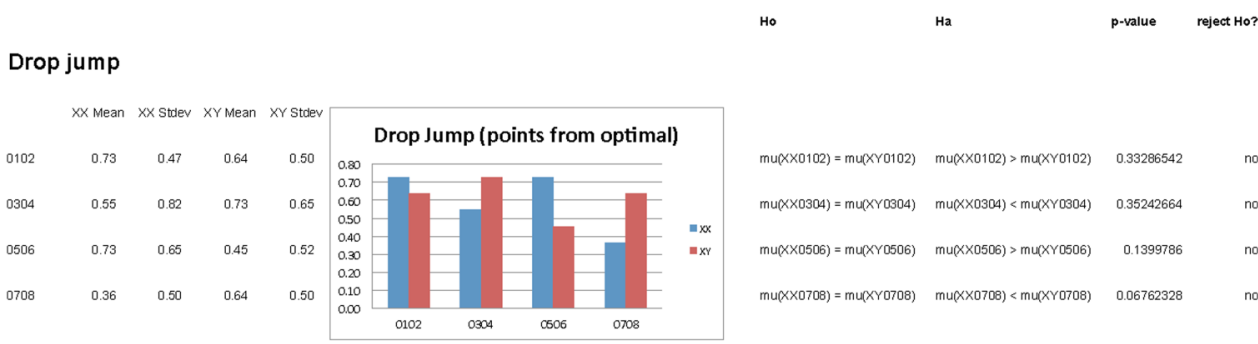

Stable Right

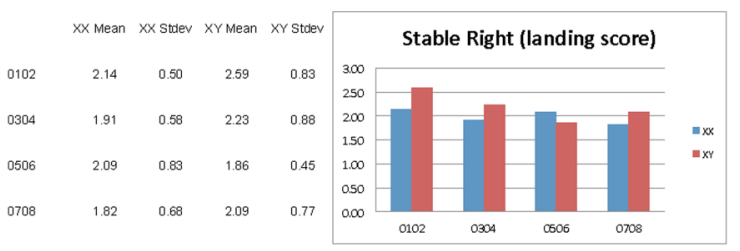

$m u(X \times 0102)=m u(X Y 0102) \quad m u(X \times 0102)<m u(X Y 0102) \quad 0.07000919 \quad$ yes

$\operatorname{mu}(x \times 0304)=\operatorname{mu}(x Y 0304) \quad \operatorname{mu}(x \times 0304)<\operatorname{mu}(X Y 0304) \quad 0.20253049 \quad$ no

$m u(X \times 0506)=m u(x Y 0506) \quad m u(x \times 0506)>\operatorname{mu}(X Y 0506) \quad 0.33024824 \quad$ no

$\operatorname{mu}((X 0708)=\operatorname{mu}(X Y 0708) \quad \operatorname{mu}(X \times 0708)<\operatorname{mu}(X Y 0708) \quad 0.11335358 \quad$ no

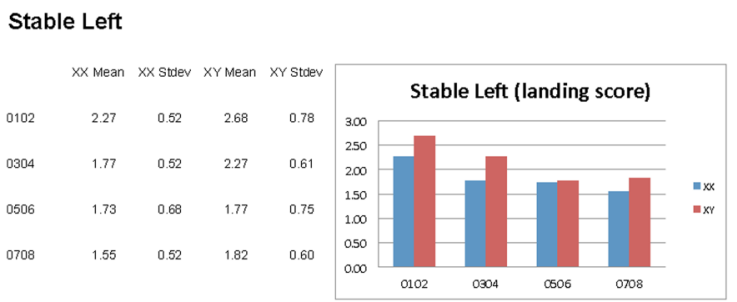

$\operatorname{mu}(x \times 0304)=\operatorname{mu}(x \times 0304) \quad \operatorname{mu}(x \times 0304)<\operatorname{mu}(x \times 0304) \quad 0.00482356$

$m u(X \times 0506)=m u(X Y 0506) \quad m u(X X 0506)<m u(X Y 0506) \quad 0.26812753$

$\operatorname{mu}(\times \times 0708)=\operatorname{mu}(x Y 0708) \quad \operatorname{mu}(\times \times 0708)<\operatorname{mu(XY0708)} \quad 0.07726827$

Unstable Right

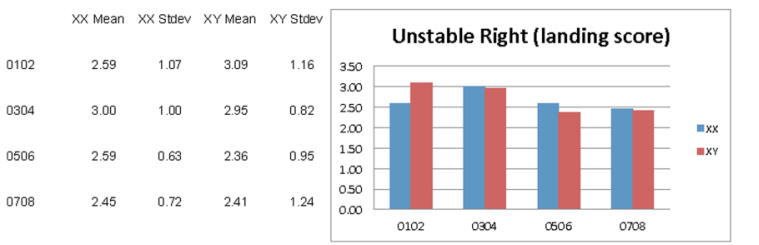

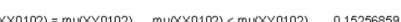

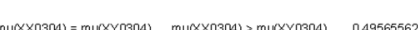

$\operatorname{mu}(X \times 0506)=\operatorname{mu}(X Y 0506) \quad \operatorname{mu}(X X 0506)>\operatorname{mu}(X Y 0506) \quad 0.2595481$

$\operatorname{mu}(x \times 0708)=\operatorname{mu}(x Y 0708) \quad m u(X \times 0708)>\operatorname{mu}(x \times 0708) \quad 0.41588257$

Unstable Left
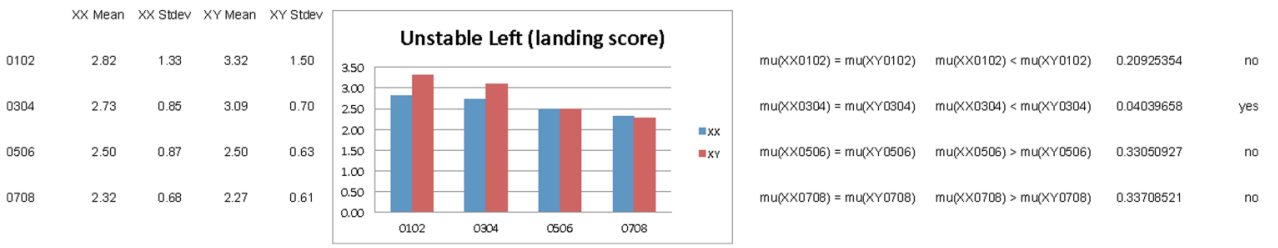

Figure 3 The $\chi^{2}$ analyses demonstrating which by comparison which at which age preadolescents are able to demonstrate a significant difference on single-leg balance testing and modified drop-jump testing.

figure 3). Overall, the inspection of the graphics appeared to reveal a trend to better overall scores of the females compared with males, but this did not achieve statistical significance (figure 3). Data analysis was not able to identify a conclusive time at which the balance skills and neuromotor assessments dropped below their male counterparts placing female athletes at increased risk of ACL injury.

\section{DISCUSSION}

The relative increased risk of anterior cruciate injury in women compared with men in twisting and cutting sports has become well recognised and well documented in the literature. ${ }^{1}{ }^{2}$ While numerous factors including anatomic alignment, hormonal influences and anatomic structure (small notch, smaller ligament volume) have been considered and in some cases implicated as causative factors, targeting neuromotor retraining of core and balance deficiencies has been shown to be an effective means of injury prevention in these at-risk athletes. ${ }^{3-5} 14$ Specific studies of adolescent and young adult athletes have revealed similar sex-related variation of core and balance control when comparing trained and untrained athletes. ${ }^{10}$ While a large majority of existing studies have identified the gender variations contributing to ACL 
risk, few have targeted skeletally immature cohorts. Stracciolini $e t a l^{18}$ performed a cross-sectional review of children presenting to a dedicated children's sports medicine centre over 10 years. They concluded, in contrast to what is seen in late adolescence and early adulthood, boys aged 5-12 years had a higher ACL to total injury rate than girls $(\mathrm{p}<0.01)$. However, over time, the proportion of ACL to total injuries increased at a higher rate for girls, and by the age of 16-17 years, the ratio exceeded that seen in boys. In 2011, the National Athletic Trainer's Association did an extensive review of the literature in coming up with their position statement on overuse injuries in paediatric sports and found the highest level of evidence to support the conclusion that balance, coordination, strength and flexibility deficits are directly correlated to overuse injuries in paediatric athletes. ${ }^{14}$ Admittedly, the type and severity of injuries may be slightly different in the lighter, shorter, paediatric population due to lower energy mechanisms; nonetheless, targeting the core deficits would seem to be a reasonable target.

Little research is available to suggest when balance and core deficits present in the adolescent population and how it progresses over time, and at what specific age do girls begin to lag behind boys. ${ }^{6}{ }^{16} \quad 7 \quad$ 19-21 Barber-Westin et $a l^{22}$ analysed children aged 9-10 years and noted a large majority of both sexes landed with increased valgus position from a drop-jump test and suggested that neuromotor retraining might be indicated. The study did not conclude a specific age or time frame by which such a programme should be initiated and whether that time was different between sexes.

In this study, we elected to use single-leg balance test on a stable and unstable surface as well as a modified drop jump as our measure of lower limb neuromotor control. These measures have been previously described and validated in the literature as valid and reproducible in adult populations. ${ }^{70-13} 19$ They have also been commonly used as a screening tool for lower extremity balance and control in direct relationship to ACL injury risk. Barber-Westin et $a l^{22}$ concluded that regarding single-leg squats, 'sexed-based strength differences are not expected to become apparent until the mid-teens and children may not master complex motor skills until ten to twelve years of age'. More specifically, they found 'most kids aged nine to twelve had abnormal drop-jump tests where they fall into the knock-knee position. More girls than boys fell into a knock-kneed alignment during the drop-jump'. Croce et at concluded that knee muscular response strategies differ by developmental level but they did not identify a sex-related difference during jump landing. Hewett $e t a l^{7}$ documented deficits in drop-jump testing for female athletes at the middle school and high school levels. In our study, the female athletes did not perform worse than their male counterparts. When compared with collegiate athletes, our findings did confirm the relatively poorer performance of preadolescents compared with mature athletes; nonetheless, most of the preadolescent participants were able to complete the task. We were also able to identify poorer performance of the tasks in the youngest subgroups of our cohort, but were able to demonstrate improvement with maturity.

More specifically, we were able to identify a gradual improvement in single-leg balance and drop-jump performance for girls and boys with the girls making a slightly earlier progress between age groups 6-7 and 8-9 years compared with the boys who appeared to make their significant progress between age groups 8-9 and 10-11 years. In contrast to Barber-Westin et al, ${ }^{22}$ we were not able to demonstrate a deficit for females in the age groups compared. More specifically, we were not able to identify deficits which would place female participants $<14$ years of age at increased risk of ACL injury due to neuromotor deficits. Indeed, by visual inspection of the graphics, there appeared to be a slight predilection to improved performance by the girls compared with the boys, but this did not achieve statistical significance.

The concept that preadolescent females would have improved neuromotor performance and coordination is supported in the developmental literature. According to Largo $e t a l,{ }^{17} 23$ the impression that girls are better coordinated than boys is mainly based on two facts. First, 'girls carry out movements in complex and adaptive tasks somewhat more rapidly than boys. Also, girls show fewer associated movements during all motor activities, and therefore movements appear more harmonious'. Girls perform complex, sequential movements on a pegboard more rapidly than boys. Girls can also stand on one leg longer, and show fewer associated movements than boys. ${ }^{17} 23$ These findings are likely consistent with the findings in this study which reveal a slight predilection of improved performance in age-matched preadolescent girls compared with boys. Ultimately, a key finding for the purpose of this paper is not so much that the girls may perform slightly better than boys which is interesting, but rather that the deficits seen later in the more mature adolescents and young adult females are not yet present in this younger age group.

This study, as is the case for most research, has some potential weaknesses that should be acknowledged and taken into account by the reader. First, while the neuromotor tests performed have been validated and used in other studies, they have not necessarily been validated in this younger age group. For the case of this study, it was felt that they were the best tests available for the project. Second, in an effort to assess the effect of childhood development, we chose a convenient educational grouping which represented a general, but not exact, age grouping and a general, but not exact, educational maturity grouping. It did not represent an exact assessment of physical maturity; nonetheless, it does paint a picture of the effect of development and maturity over time. Finally, as in the case of many comparative studies, it would be nice to have greater numbers in each group to enhance the power of subsequent conclusions. 


\section{CONCLUSION}

Based on the results of this study, we can reasonably conclude:

While the grade school cohort could successfully perform drop testing and single-leg balance testing on stable and unstable surfaces, their neuromotor control scores fell below a comparison group of collegiate athletes. This, while obvious, served to establish a comparative foundation for the study.

Within the grade school cohort, it was readily evident that younger children performed more poorly than older children on all testing modalities, but their skill improved with age. By the time the children matured to the 12-13 years old subgroup, their performance more nearly mirrored that of collegiate athletes.

When comparing by gender the performance of children on the stable and unstable surface, girls appear to mature slightly earlier than boys.

Based on direct sex-related comparison of each age subgroup of the children using the drop jump and single-leg balance as measures, results failed to reveal a specific timeframe in which females began to lag behind their male counterparts. Based on this, it is reasonable to conclude that the imbalances seen in mature athletes that place female athletes at risk of ACL injury have not yet occurred in the 6-13 years old cohort studied in this evaluation.

Acknowledgements The authors would like to offer special appreciation to Julie Albert for her guidance and motivation and to David Stapleton who performed the statistical analysis for the project (stapoleta@yahoo.com).

Contributors $\mathrm{ABH}$ was the primary researcher and lead author for all facets related to the young population. PY was the key researcher regarding the mature athlete population data group and provided initial statistical analysis of the comparative groups. MRH was the senior author who provided conceptual design of project, supervised all levels of manuscript editing, and provided key input regarding appropriate references and review.

Competing interests None declared.

Ethics approval Immaculate Conception School.

Provenance and peer review Not commissioned; externally peer reviewed.

Data sharing statement The manuscript represents the core of the research, and fundamental data are included in its entirety. Original data summary documents are retained by the senior author and could be made available by request for future collaborative research with the caveat that the original published research and publisher always receive appropriate credit.

Open Access This is an Open Access article distributed in accordance with the Creative Commons Attribution Non Commercial (CC BY-NC 4.0) license, which permits others to distribute, remix, adapt, build upon this work noncommercially, and license their derivative works on different terms, provided the original work is properly cited and the use is non-commercial. See: http:// creativecommons.org/licenses/by-nc/4.0/

\section{REFERENCES}

1. Agel J, Arendt EA, Bershadsky B. Anterior cruciate ligament injury in national collegiate athletic association basketball and soccer: 13-year review. Am J Sports Med 2005;33:524-30.
2. Arendt $E$, Dick R. Knee injury patterns among men and women in collegiate basketball and soccer. NCAA data and review of literature. Am J Sports Med 1995;23:694-701.

3. Huston LJ, Greenfield ML, Wojtys EM. Anterior cruciate ligament injuries in the female athlete. Potential risk factors. Clin Orthop Relat Res 2000;(372):50-63.

4. Grimm NL, Jacobs JC Jr, Kim J, et al. Anterior cruciate ligament and knee injury prevention programs for soccer players: a systematic review and meta-analysis. Am J Sports Med 2015;43:2049-56.

5. Zazulak BT, Hewett TE, Reeves NP, et al. Deficits in neuromuscular control of the trunk predict knee injury risk: a prospective biomechanical-epidemiologic study. Am J Sports Med 2007;35:1123-30

6. Croce RV, Russell PJ, Swartz EE, et al. Knee muscular response strategies differ by developmental level but not gender during jump landing. Electromyogr Clin Neurophysiol 2004:44:339-48.

7. Hewett TE, Myer GD, Ford KR, et al. Preparticipation physical examination using a box drop vertical jump test in young athletes: the effects of puberty and sex. Clin J Sport Med 2006;16:298-304.

8. Hewett TE, Myer GD, Ford KR. Decrease in neuromuscular control about the knee with maturation in female athletes. J Bone Joint Surg Am 2004;86:1601-8.

9. Myer GD, Ford KR, Khoury J, et al. Biomechanics laboratory-based prediction algorithm to identify female athletes with high knee loads that increase risk of ACL injury. Br J Sports Med 2011;45:245-52.

10. Noyes FR, Barber-Westin SD. Neuromuscular retraining intervention programs: do they reduce noncontact anterior cruciate ligament injury rates in adolescent female athletes? Arthroscopy 2014;30:245-55.

11. Quatman CE, Ford KR, Myer GD, et al. Maturation leads to gender differences in landing force and vertical jump performance: a longitudinal study. Am J Sports Med 2006;34:806-13.

12. Willson JD, Ireland ML, Davis I. Core strength and lower extremity alignment during single leg squats. Med Sci Sports Exerc 2006;38:945-52.

13. Davies PS. Assessment of cognitive development in adolescents by means of neuropsychological tasks [dissertation]. Laramie, Wyoming, USA: University of Wyoming, 1995.

14. Valovich-McLeod TC, Decoster LC, Loud KJ, et al. National Athletic Trainer's Association Position Statement: prevention of pediatric overuse injuries. J Ath/ Train 2011;46:206-20.

15. Davies PL, Rose JD. Motor skills of typically developing adolescents: awkwardness or improvement? Phys Occup Ther Pediatr 2000;20:19-42.

16. Ford KR, van den Bogert J, Myer GD, et al. The effects of age and skill level on knee musculature co-contraction during functional activities: a systematic review. Br J Sports Med 2008:42:561-6.

17. Largo RH, Caflisch JA, Hug F, et al. Neuromotor development from 5 to 18 years. Part 2: associated movements. Dev Med Child Neurol 2001:43:444-53.

18. Stracciolini A, Stein CJ, Zurakowski D, et al. Anterior cruciate ligament injuries in pediatric athletes presenting to sports medicine clinic: a comparison of males and females through growth and development. Sports Health 2015;7:130-6.

19. Kernozek TW, Torry MR, van $\mathrm{Hoof} \mathrm{H}$, et al. Gender differences in frontal and sagittal plane biomechanics during drop landings. Med Sci Sports Exerc 2005;37:1003-12.

20. Quatman CE, Ford KR, Myer GD, et al. The effects of gender and pubertal status on generalized joint laxity in young athletes. $J \mathrm{Sci}$ Med Sport 2008;11:257-63.

21. Shea KG, Pfeiffer R, Wang JH, et al. Anterior cruciate ligament injury in pediatric and adolescent soccer players: an analysis of insurance data. J Pediatr Orthop 2004:24:623-8.

22. Barber-Westin SD, Galloway M, Noyes FR, et al. Assessment of lower limb neuromuscular control in prepubescent athletes. $A m \mathrm{~J}$ Sports Med 2005;33:1853-60.

23. Largo RH, Caflisch JA, Hug F, et al. Neuromotor development from 5 to 18 years. Part 1: timed performance. Dev Med Child Neurol 2001;43:436-43. 